\title{
Preliminary study for acetylation of cassava bagasse starch and microfibrillated cellulose of bamboo
}

\author{
Silviana Silviana $^{l *}$, Siti Susanti ${ }^{2}$, and Agus Subagio $^{3}$ \\ ${ }^{1}$ Department of Chemical Engineering, Faculty of Engineering, Diponegoro University, Jl. Prof. Sudarto, SH., Kampus Tembalang \\ Semarang, 50275, Indonesia \\ ${ }^{2}$ Department of Food Technology, Faculty of Agriculture, Diponegoro University, Jl. Prof. Sudarto, SH., Kampus Tembalang Semarang, \\ 50275, Indonesia \\ ${ }^{3}$ Department of Physics, Faculty of Science and Mathematics, Diponegoro University, Jl. Prof. Sudarto, SH., Kampus Tembalang \\ Semarang, 50275, Indonesia
}

\begin{abstract}
Bio composite matrixes have been developed from several biomaterials, such as starch. One of potential resources is starch isolated from cassava bagasse still consisting 30-50\% of starch. Reinforcement material may be inserted into bio composite to tough and reduce the drawback of the starch-based bio composite or bio plastic. Microfibrillated cellulose of bamboo (MFC) can be used as toughening filler for composite matrix. However, surface modification of material could be employed to alter its properties, such as acetylation of starch-based bio composite and microfibrillated cellulose. The acetylation was executed by using glacial acetic acid (GAA) catalyzed with sodium hydroxide. This paper investigates optimum condition of acetylation for bagasse starch (BS) and bamboo MFC in different weight ratio of GAA to BS or MFC $(1: 1,2: 1,3: 1,1: 2,1: 3)$, temperature range of $30^{\circ} \mathrm{C}$ to $70^{\circ} \mathrm{C}$, and $\mathrm{pH}$ range of 7 to 11 . Data were resulted from degree of susbtitution for each running. The optimum condition of acetylation of BS was obtained at temperature of $50^{\circ} \mathrm{C}$ (for BS) and $30^{\circ} \mathrm{C}$ (for MFC), $\mathrm{pH}$ of 9, and 2:1 ratio. This acetylation was confirmed by fourier transform infrared spectroscopy and scanning electron microscope.
\end{abstract}

\section{Introduction}

Starch, an inexpensive natural resource, has been utilized in several fields, mostly in food area regard with sustainability, economic, and biodegradable. Furthermore, environment issue about replacement commercial plastics is harvesting by raising the demand bioplastic with renewable sources. Starch-based bioplastic have been employed several sources, such as banana [1], potato [2], sago [2-5], rice [6], corn [7], soybean [8], and cassava [9]. Cassava starch has been broadly utilized to be used in bioplastic reinforced with clay nanoparticles [9], thermoplastic chitosan [7], poly lactic acid [10], gelatin [11], bamboo nanofibrils [12], bacterial cellulose [13], and green coconut fiber [14] in order to overcome drawbacks of starch-based bioplastic, such as mostly water-soluble, low resitancy, and low mechanical property. Cassava starch production generates by-product [9], i.e cassava bagasse or pulp consisted a fibrous material containing $30-60 \%$ residual starch [15]. Due to low cyanide content with low protein it makes unattractive as ruminant. Furthermore, low ash content denotes broadly usage as biorefinery using microbial cultures [16]. Mostly, this solid is released as wasted resources. By using thermoplastic behaviour of residual starch in cassava bagasse, starch-rich cassava bagasse is promising future feedstock as global bioplastic packaging to replace commercial plastic with high underutilized and inexpensive. In this research it was considered to prepare bioplastic or cassava bagasse starch-based biocomposite reinforced with microfibrillated cellulose of bamboo, bamboo cellulose fiber. Bamboo denotes as potential fiber sources for biocomposites matrix [17-18], as composite filler for polyvinylchloride (PVC) [15], reinforcing nanocomposite starch-polyvinylacetate (PVA) [12], reinforcing polylactic acid (PLA) [20], reinforcing starch-based composite [21]. However, both (cassava bagasse starch and bamboo microfibrillated cellulose) have shortcomings regard with their properties. Therefore, it would be introduced by chemical modification such as acetylation. Acetylation is esterification reaction of acetyl group with hydroxyl group in starch-rich cassava bagasse (BS) and bamboo microfibrillated cellulose (MFC) to form starch acetates and cellulose acetates. This modification is expected to enhance translucency, stability, retrogradation, decrease gelatinasation temperature. Furthermore, dispersing bamboo microfibrillated cellulose in nonpolar or lowpolar media can be improved by acetylation of the

Corresponding author: silviana@che.undip.ac.id 
primary hydroxyl groups [22]. This paper reviews investigation for acetylation of cassava bagasse and bamboo microfibrillated cellulose by using glacial acetic acid (GAA) with sodium hydroxide as catalyst. The objectives of this paper are to obtain optimum condition of acetylation such as $\mathrm{pH}$, temperature, and ratio of GAA to BS and GAA to MFC. The assessments of result were confirmed by degree of substitution (DS), fourier transform infrared (FTIR), scanning electron microscope (SEM), and differential scanning calorimetry (DSC).

\section{Materials and methods}

\subsection{Materials}

Cassava bagasse was delivered from small entrepreneurship in Pati. Bamboo feedstock was supplied from Sragen, Central Java. Glacial acetic acid was provided from Merck (100\%). Sodium hydroxide was supplied from Merck (99\%). Hydrochloric acid with $37 \%$ was produced from Mallinckrodt Chemicals-USA. Potasium hydroxide pro analysis 99\% was provided from Merck. Phenolphthalein also was supplied from Merck. Hydrogen peroxide $\left(\mathrm{H}_{2} \mathrm{O}_{2}\right) 50 \%$ was produced by Evonik Industries, Indonesia and alcohol 96\% were produced by $\mathrm{PT}$. Indo Acidatama, Tbk, Indonesia. Toluene $99.5 \%$ was provided from Mallinckrodt Chemicals-USA.

\subsection{Characterization}

Assessment of products were introduced by FTIR Fourier Transform Infrared Spectroscopy. The measurements were obtained using a FTIR model IR Prestige 21, Shimadzu. Spectra were recorded at a spectral range between 400 and $4000 \mathrm{~cm}-1$ at a scan rate of 40 scans and spectral resolution of $4 \mathrm{~cm}^{-1}$. The FTIR spectrum was employed in the absorbance mode. FTIR analyses were performed to study the effect of the acetylation. The matrix of BS and bamboo MFC were observed surface morphology by using scanning electron microscopy (SEM type Inspect S50, FEI). Thermal properties were determined by using differential scanning calorimetry (DSC 60, Shimadzu). Measurements conducted with a refrigerated cooling system (RCS) and a nitrogen DSC cell purge at 30 $\mathrm{ml} / \mathrm{min}$ was used to achieve temperatures range of $30^{\circ} \mathrm{C}$ to $300{ }^{\circ} \mathrm{C}$.

\subsection{Methods}

Preparation of cassava bagasse was executed by washing and sizing. The bagasse was dissolved in water and filtered a filter cloth. Filtrat was collected and then left a few days. The water at the top of the precipitate was removed, while the precipitate was collected. The sun dried precipitated slurry. After drying, the starch was then sieved to obtain the cassava bagasse starch with fine powder. This powder was homogenized by using high energy milling for one hour. The bamboo stem was cut and chopped prior sizing into mini crusher releasing bamboo powder. Then powdered bamboo stem was sieved to $150 \mu \mathrm{m}$ size. The bamboo powder was then washed with $90^{\circ} \mathrm{C}$ hot water three times to reduce the impurities. The isolation process of bamboo MFC was done by extraction using toluene- alcohol $(2: 1)$ for 6 hours. The delignification process for the removal of hemicellulose was conducted with a $2 \% \mathrm{w} / \mathrm{v}$ potassium hydroxide $(\mathrm{KOH})$ solution heated at $90^{\circ} \mathrm{C}$ with magnetic stirrer. Then, delignified bamboo was filtered and dried at room temperature. Bleaching process removing lignin was executed by $4 \% \mathrm{v} / \mathrm{v}$ hydrogen peroxide $\left(\mathrm{H}_{2} \mathrm{O}_{2}\right)$ solution heated at $50^{\circ} \mathrm{C}$. Then, it was filtered and washed with aquadest up to neutral $\mathrm{pH}$. Furthermore, the bamboo MFC was dried at $105^{\circ} \mathrm{C}$ for 24 hours. MFC bamboo was homogenized in size by high energy milling. This preparation was conducted with slight modification of previous research [23-24]. Both acetylation was considered to follow Kumoro \& Amalia (2015) procedure [25] and also degree of substitution (DS) for BS and bamboo MFC. Starch solution can be prepared by dissolution of BS in aquadest with $4 \mathrm{wt} \%$. The solution was adjusted certain $\mathrm{pH}$ by using $1 \mathrm{M}$ $\mathrm{NaOH}$. This solution was then stirred for 30 minutes. Certain mass of GAA was gradually added to the solution, while controlling at constant a $\mathrm{pH}$ to certain value of variables. Acetylation reaction would be accomplished at certain time by pouring $1 \mathrm{M} \mathrm{HCl}$ having $\mathrm{pH}$ of 5.5. The acetylated products were filtrated and washed the product by using aquadest. Washed product was then dried in oven at $50{ }^{\circ} \mathrm{C}$ prior to degree substitution analysis [26]. The certain acetylated product was dissolved in ethanol $(50 \mathrm{ml}$ of $75 \mathrm{ml}$ ethanol in 100 $\mathrm{ml}$ of water) into flask. Afterward, this solution was agitated for $30 \mathrm{~min}$ at temperature of $50{ }^{\circ} \mathrm{C}$. Then, the solution was cooled and added $40 \mathrm{ml}$ of $0.5 \mathrm{M} \mathrm{KOH}$. The residual alkali was back titrated with $0.5 \mathrm{M} \mathrm{HCl}$ using phenolphthalein as indicator. A blank, each unacetylated substances was used. Calculation of degree substitution uses the following equation.

$$
\% \text { Acetyl }=\frac{\left(V_{0}-V_{n}\right) \times M H C l \times 0.043 \times 100}{M}
$$

$D S=\frac{162 \times \% \text { Acetyl }}{4300-(42 \times \% \text { Acetyl })}$

Where $V_{0}$ is volume of required $\mathrm{HCl}$ for blank sample. $V_{\mathrm{m}}$ is volume of required $\mathrm{HCl}$ for sample. Normality of $\mathrm{HCl}$ is denoted by $\mathrm{N}$. $\mathrm{M}$ is dried sample weight.

\section{Results and discussion}

\subsection{Degree of substitution}

Observation of optimum condition ( $\mathrm{pH}$, temperature, and ratio of GAA to $\mathrm{BC}$ or bamboo MFC) based on degree 
substitution have been conducted. In this research, at beginning the optimum $\mathrm{pH}$ was investigated first at temperature of $40{ }^{\circ} \mathrm{C}$, ratio of GAA to $\mathrm{BS}$ or bamboo MFC (2:1) and reaction time of 40 minutes. The optimum $\mathrm{pH}$ can be attained at 9 , while increasing $\mathrm{pH}$ can occur decreasing degree of substitution. Acetylated BS obtained DS of 0.22 , while acetylated bamboo MFC gained DS of 0.41 at $\mathrm{pH}$ of 9 . Acetylation percentage denoted the same trending with. It could be expected for increasing $\mathrm{pH}$ releasing hydrolysis reaction regard with decreasing acetyl group and increasing residual acetic acid in the bulk liquid [27-28]. Increasing $\mathrm{pH}$ may affect starch to undergo partial gelatinization under alkaline resulting high solubility. High solubility may be denoted to weakening of granule structure during modification [29]. This result can be seen in Fig. 1 below.

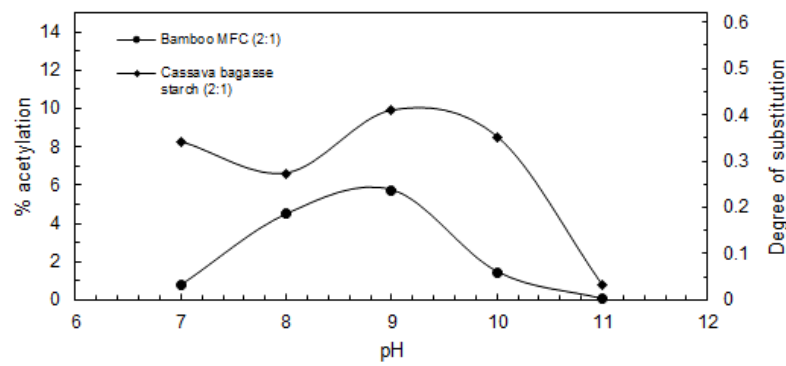

Fig. 1. Effect of increasing $\mathrm{pH}$ in acetylation of $\mathrm{BS}$ and bamboo MFC with ratio of 2:1 (GAA/BS or bamboo MFC)

By using optimum $\mathrm{pH}$, the acetylation reaction was further conducted to obtain optimum temperature. It can been seen in Fig.2 that optimum temperature can be reached at $60{ }^{\circ} \mathrm{C}$ for acetylated bamboo MFC and at 50 ${ }^{\circ} \mathrm{C}$ for acetylated BS. It can be confirmed that due to reversible reaction of acetylation, increasing temperature can increase the solubility of starch (BS). It may be correlated to loss of granular structure and generates of amylase fraction of the starch as the amylase molecules are solubilized and leached from swollen starch (Alam \& Hasnain, 2009)

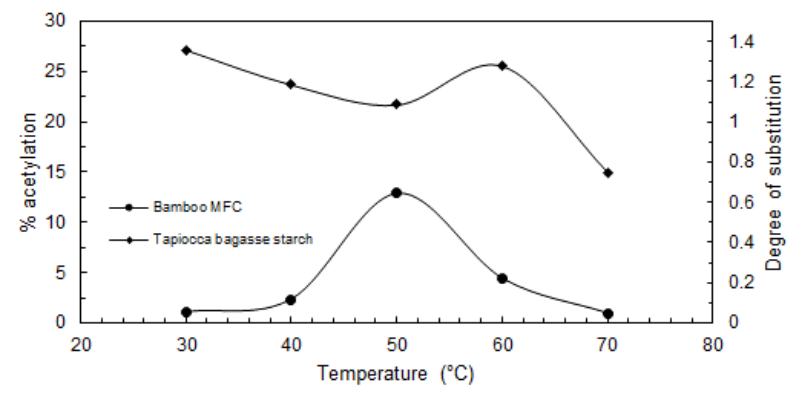

Fig. 2. Effect of increasing temperature in acetylation of BS and bamboo MFC with ratio of 2:1 (GAA/BS or bamboo MFC)

Optimum $\mathrm{pH}$ and temperature were used on next observation to obtain optimum ratio of GAA to BS or bamboo MFC. Fig. 3 represented that optimum DS and also \% acetylation of GAA over BS or bamboo MFC can occur at 2:1. At beginning, increasing concentration of acetic acid (GAA) released higher DS (0.93 for bamboo MFC and 0.47 for BS), but unfortunately afterward the DS steep down to 0.5 and 0.1 for bamboo MFC and BS, respectively. It can be seen more acid concentration, more residual acid in the bulk phase. In the beginning, the acid can diffuse and withstand adsorption to the BS and MFC. However, for higher amount of BS or MFC did not occur more acetylation regard with less amount of the acid concentration in the bulk phase.

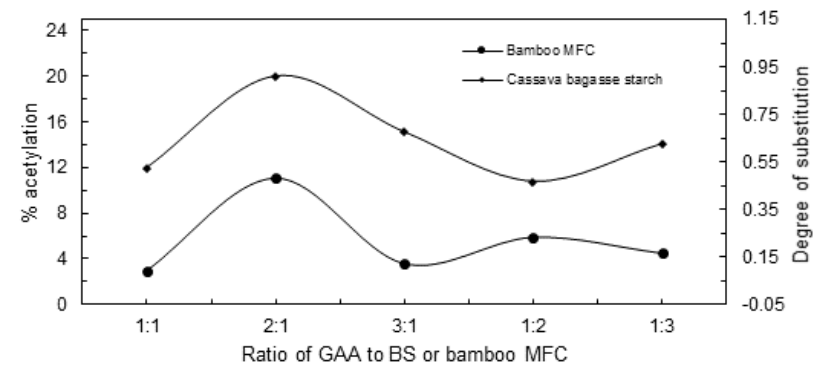

Fig. 3. Effect of increasing reaction time in acetylation of BS and bamboo MFC with $\mathrm{pH}$ of 9 and ratio of 2:1 (GAA/BS or bamboo MFC)

\subsection{Thermal analysis}

Table 1 shows the effect of acetylation on the thermal analysis of the properties of BS or bamboo MFC. The onset $\left(T_{\mathrm{o}}\right)$, peak $\left(T_{\mathrm{p}}\right)$, and final $\left(T_{\mathrm{c}}\right)$ temperature of gelatinization were lower in the presence of acetyl group although the enthalpy $(\Delta H)$ was hardly affected by acetylation. This shift to lower temperature for gelatinization indicated that $\mathrm{BS}$ or bamboo MFC gelatinized easily with the addition of acetyl group. DSC result of acetylated BS and acetylated bamboo MFC can be seen in Fig. 4 and Fig.5, respectively.

Table 1. DSC characteristics of native and acetylated BS or bamboo MFC.

\begin{tabular}{|l|c|c|c|c|}
\hline \multirow{2}{*}{} & \multicolumn{3}{|c|}{ Endothermal } & \multirow{2}{*}{$\Delta \mathrm{H}(\mathrm{J} / \mathrm{g})$} \\
\cline { 2 - 4 } & $\mathrm{T}_{0}$ & $\mathrm{~T}_{\mathrm{P}}$ & $\mathrm{T}_{\mathrm{C}}$ & \\
\hline $\begin{array}{l}\text { Acetylated } \\
\text { MFC }\end{array}$ & 65.23 & $\begin{array}{c}101 . \\
27\end{array}$ & $\begin{array}{c}133 . \\
81\end{array}$ & 173.74 \\
\hline Native MFC & 81.15 & $\begin{array}{c}111 . \\
2\end{array}$ & $\begin{array}{c}142 . \\
60\end{array}$ & \multirow{2}{*}{183.44} \\
\hline $\begin{array}{l}\text { Acetylated } \\
\text { BS }\end{array}$ & 82.15 & $\begin{array}{c}109 . \\
21\end{array}$ & $\begin{array}{c}155 . \\
96\end{array}$ & 207.15 \\
\hline Native BS & 86.3 & $\begin{array}{c}112 . \\
24\end{array}$ & $\begin{array}{c}159 . \\
27\end{array}$ & 209.34 \\
\hline
\end{tabular}




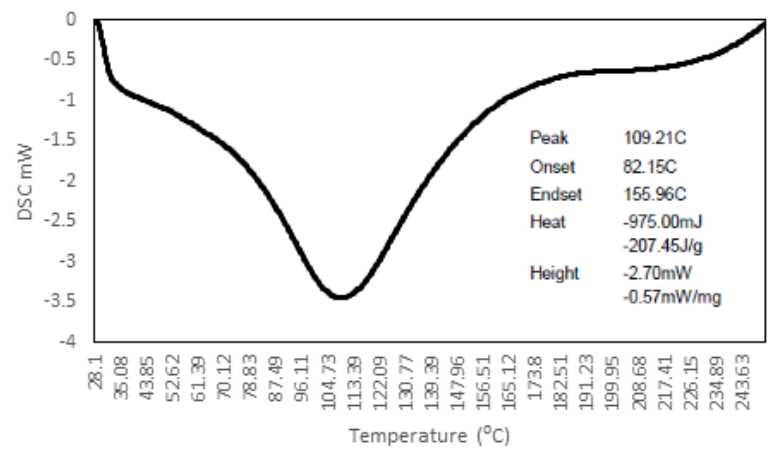

Fig. 4. DSC analysis of acetylated BS

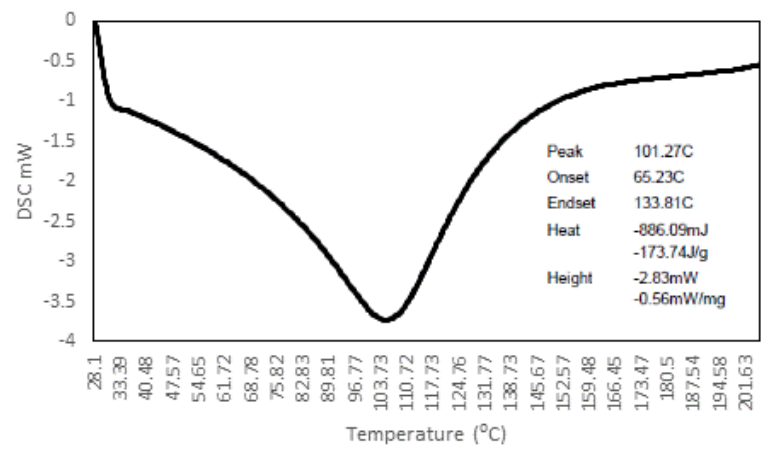

Fig. 5. DSC analysis of acetylated BS

\subsection{SEM analysis}

Native BS granules have a regular elliptical shape and smooth surface while native MFC have thin flat. After acetylation, both resulted deformation of granules or flat due to the temperature of acetylation as result of the structure reorganization. It is recognized with Fig.6(a) to Fig.6(d). These figures confirm with native bamboo MFC, native BS, acetylated bamboo MFC, and acetylated BS, respectively.

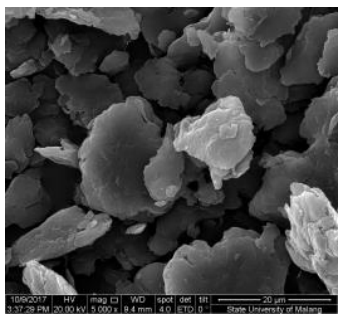

(a)

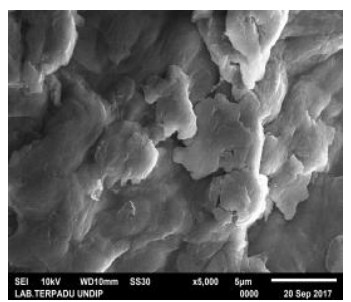

(c)

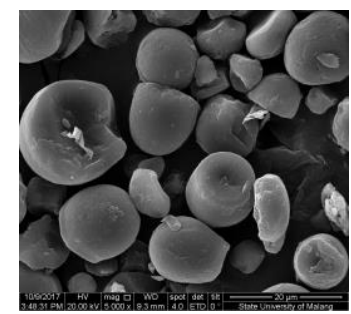

(b)

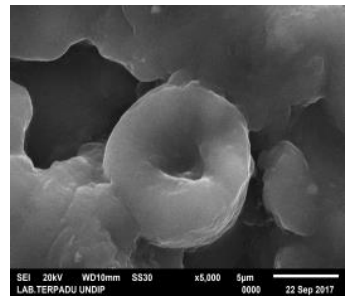

(d)
Fig. 6. SEM analysis of native bamboo MFC (a), native BS (b), acetylated bamboo MFC (c), and acetylated BS (d) with magnification of $5000 x$

\subsection{FTIR analysis}

Acetylated BS/MFC denoted lower absorbance value than that of native $\mathrm{BS} / \mathrm{MFC}$ expressing decrease of functional group number while in the product did not have significant acetyl group at $1750 \mathrm{~cm}^{-1}$ only a slight peak around $1732 \mathrm{~cm}^{-1}$ for acetylated MFC and none acetyl group for acetylated BS only decrease in absorption of $\mathrm{OH}$ group. These results can be visualized in Fig.7. and Fig.8. for native and acetylated BS, then native and acetylated bamboo MFC, respectively.

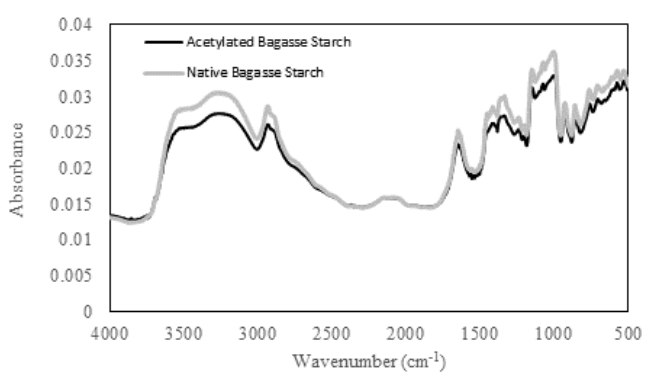

Fig. 7. FTIR analysis of native and acetylated BS

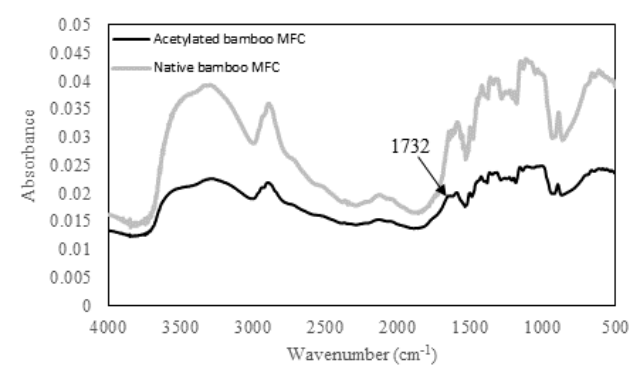

Fig. 8. FTIR analysis of native and acetylated bamboo MFC

\section{Conclusion}

The optimum condition of acetylation such as $\mathrm{pH}$, temperature, and ratio of GAA to BS and GAA to MFC can be further used to observe the kinetic mechanism of acetylation for BS and bamboo MFC to know rate controlling step of the acetylation, i.e. regime of mass transfer or chemical reaction. The acetylation for BS and bamboo MFC can affect physicochemical, and thermal properties, in terms of the structural, the thermal, and the morphology. It was confirmed by FTIR, DSC, and SEM analysis.

\section{References}

1. Pelissari, F. M., Andrade-Mahecha, M. M., Sobral, P. J. D. A., \& Menegalli, F. C., Food Hydrocoll. 30, 2 (2013)

2. Menzel, C. Doctoral Thesis (2014)

3. Al-Hassan, a. a., \& Norziah, M. H., Food Hydrocoll. 26, 1 (2012) 
4. Silviana, S. \& Anggoro, D. D., Adv. Sci. Lett. 23, 3 (2017)

5. Silviana, S. \& Hadiyanto, H., AIP Conf. Proc. 1885, 030024 (2017)

6. Dias, A. B., Müller, C. M. O., Larotonda, F. D. S., \& Laurindo, J. B., J Cereal Sci. 51, 2 (2010)

7. Mendes, J. F., Paschoalin, R. T., Carmona, V. B., Sena Neto, A. R., Marques, a. C. P., Marconcini, J. M., Mattoso, L.H.C., Medeiros, E.S., Oliveira, J. E., Carbohydr Polym. 137 (2016)

8. Tajik, S., Maghsoudlou, Y., Khodaiyan, F., Jafari, S. M., Ghasemlou, M., \& Aalami, M., Carbohydr Polym. 97, 2 (2016)

9. Souza, a. C., Benze, R., Ferrão, E. S., Ditchfield, C., Coelho, a. C. V, \& Tadini, C. C., LWT-Food Sci Technol. 46, 1 (2012)

10. Teixeira, E. D. M., Curvelo, A. A. S., Corrêa, A. C., Marconcini, J. M., Glenn, G. M., \& Mattoso, L. H. C., Ind Crops Prod. 37 (2012)

11. Acosta, S., Jimenez, A., Chafer, M., GonzalezMartinez, C., \& Chiralt, A., Food Hydrocoll. 49 (2015)

12. Guimarães, M., Botaro, V. R., Novack, K. M., Teixeira, F. G., \& Tonoli, G. H. D., Ind Crops Prod. 70 (2015)

13. Martins, I. M. G., Magina, S. P., Oliveira, L., Freire, C. S. R., Silvestre, A. J. D., Neto, C. P., \& Gandini, A., Compos. Sci. Technol. 69, 13 (2009)

14. Lomelí-Ramírez, M. G., Kestur, S. G., ManríquezGonzález, R., Iwakiri, S., de Muniz, G. B., \& Flores-Sahagun, T. S., Carbohydr Polym. 102 (2014)

15. Sánchez, S. A., Lopes, Y., Araújo, R., \& Cohim, E., RSER 73 (2017)

16. Pandey, A., Soccol, C. R., Nigam, P., Soccol, V. T., Vandenberghe, L. P. S., \& Mohan, R., Bioresour. Technol. 74, 1 (2000)

17. Abdul Khalil, H. P. S., Alwani, M. S., Islam, M. N., Suhaily, S. S., Dungani, R., H'ng, Y. M., \& Jawaid, M., In book: Biofiber Reinforcements in Composite Materials, Chapter 16, Woodhead Publishing USA (2015)

18. Thakur, V. K., \& Thakur, M. K., Carbohydr Polym. 109 (2014)

19. Bahari, S. A., \& Krause, A., J Clean Prod. 110 (2016)

20. Lu, T., Liu, S., Jiang, M., Xu, X., Wang, Y., Wang, Z., Gou, J., Hui, D., Zhou, Z., Compos Part B Eng. 62 (2014)

21. Liu, D., Zhong, T., Chang, P. R., Li, K., \& Wu, Q., Bioresour. Technol. 102 (2010)

22. Bulota, M., Hughes, M., \& Paltakari, J., J Appl Polym Sci. 126 (2012)

23. Chen, H., Wang, W., Martin, J. C., Oliphant, A. J., Doerr, P. a., Xu, J. F., Deborn, K.M., Chen, C., Sun, L., ACS Sustain Chem Eng. 1, 2 (2013)
24. Nguyen, H. D., Thuy Mai, T. T., Nguyen, N. B., Dang, T. D., Phung Le, M. L., Dang, T. T., \& Tran, V. M., Adv. Nat. Sci.: Nanosci. Nanotechnol. 4, 1 (2013)

25. Kumoro, A.D. \& Amalia, R., BCREC 10, 1 (2015)

26. Sodhi, N. S., \& Singh, N., J Food Eng. 70 (2005)

27. Song, X., He, G., Ruan, H., Chen, Q. Starch/Stärke, 58 (2006)

28. Luo, Z.G., Zhou, Z., Starch/Stärke, 64 (2012)

29. Alam, F., \& Hasnain, A., Agric. conspec. sci. 74, 1 (2009) 